\title{
MONITORING POST-DISASTER MANGROVE FOREST RECOVERIES IN LAWAAN- BALANGIGA, EASTERN SAMAR USING TIME SERIES ANALYSIS OF MOISTURE AND VEGETATION INDICES
}

\author{
K. V. Ticman ${ }^{1 *}$, S. G. Salmo III ${ }^{2}$, K. E. Cabello ${ }^{1}$, M.Q. Germentil ${ }^{1}$, D. M. Burgos ${ }^{1}$, A.C. Blanco ${ }^{1,3}$ \\ ${ }^{1}$ Department of Geodetic Engineering, College of Engineering, University of the Philippines Diliman - (kvticman2, kecabello, \\ mqgermentil, dmburgos)@up.edu.ph \\ ${ }^{2}$ Institute of Biology, College of Science, University of the Philippines Diliman - sgsalmo@up.edu.ph, \\ ${ }^{3}$ Training Center for Applied Geodesy and Photogrammetry, University of the Philippines Diliman - acblanco@up.edu.ph
}

KEY WORDS: Mangroves; Landsat 8; time series; NDVI; EVI; MSAVI; NDMI.

\begin{abstract}
:
The mangrove forests of Lawaan-Balangiga in Eastern Samar lost significant cover due to the Typhoon Haiyan that struck the region in 2013. The mangroves in the area have since shown signs of recovery in terms of growth and spatial coverage, but these widely varied with locations. This study aims to further examine the status of recovery of mangroves across different locations by analysing the time series trends of selected vegetation and moisture indices: Normalized Difference Vegetation Index (NDVI), Enhanced Vegetation Index (EVI), Modified Soil Adjusted Vegetation Index (MSAVI), and Normalized Difference Moisture Index (NDMI). These indices were extracted from Landsat 8 surface reflectance images, spanning 2014 to 2020, using Google Earth Engine (GEE). The time series analyses showed similar NDVI, MSAVI and NDMI values and trends after the 2013 typhoon event. The trend slopes also indicated high correlation $(0.91-1.00)$ between and among the indices, with NDVI having the highest correlation with MSAVI ( 1.00). The study was able to corroborate the previous study on mangroves in Lawaan-Balangiga, by presenting positive trend results in the identified recovered areas. These trends, however, would still have to be validated by collecting and comparing biophysical parameters in the field. The next step of the research would be to identify the factors that contribute to the varying rates of recovery in the areas and to evaluate how this can affect the carbon sequestration rates of recovering mangroves.
\end{abstract}

\section{INTRODUCTION}

\subsection{The ecosystem services of mangroves}

Mangroves are a group of trees and shrubs that grow in the coastal intertidal zone, making up for one of the most productive ecosystems in the world (IUCN, 2021; NOAA, 2021). They are vulnerable environmental resources that provide significant economic goods and services that contribute to human well-being (Conservation International, 2008). They support fisheries, are valued sources of timber and fuel, and provide tourism opportunities. They even contribute to climate regulation through carbon sequestration (Sarhan \& Tawfik, 2018). More importantly, mangroves are effective in providing coastal protection to communities, through its aerial roots that trap and retain sediments, preventing erosion; its roots, trunks and canopies can significantly reduce the force of wind, waves and flood waters (Losada et al., 2017).

The protective services of mangroves are especially valuable in disaster-prone areas such as the Philippines. When super typhoon Haiyan struck the country in 2013, it was packing winds registered over $300 \mathrm{kph}$ - one of the strongest in history for the landfall of a cyclone (FAO, 2021). It made several landfalls along the Visayas group of islands. The provinces of Eastern Samar and Leyte took the brunt of the category 5 storm, bringing sustained winds of up to $245 \mathrm{kph}$ and an even more destructive storm surge. The super typhoon affected more than 14 million people and cost an estimated damage at US $\$ 5.8$ billion across the country (World Vision, 2021). However, several coastal villages in the Eastern Samar and Leyte with substantial mangrove cover suffered significantly less damage from the storm surge compared to the bare and open coastal communities (Delfino et al., 2015; Seriño et al., 2017). Even local narratives (Delfino et al., 2015; The World, 2021) recognize the critical role that mangroves have in the protection of the community.

\subsection{Post-disaster mangrove recovery}

The extent of damage to mangrove forests nationwide was estimated to be around 8,568 hectares, or $3.5 \%$ of the total mangrove forest area in the Philippines. Most of the damaged mangroves were identified in the provinces of Eastern Samar, Western Samar, and Leyte. Nevertheless, in as early as 18 months after the typhoon, mangrove forests have shown signs of recovery (Long et al., 2016). An assessment on the post typhoon recovery in the Lawaan-Balangiga areas in Eastern Samar (Cabello et al., 2021), showed growth trends and increased spatial cover.

Cabello et. al. (2021) assessed the damage to the mangroves and the subsequent recovery through a time series analysis of mean Normalized Difference Vegetation Index (NDVI) values in the coastal towns. Landsat 8 images, covering years from 2013 to 2019, were processed in Google Earth Engine (GEE). Trends in the NDVI values were divided into three different sections, namely (a) Damage Period (2013-2014), (b) Recovering Period (2014-2017), and (c) Stabilizing Period (2017-2019). NDVI values in the Recovery Period indicated a rapid and steady growth of mangroves. Areas with sustained recovery as opposed to delayed recovery and no recovery were also identified. The study employed a wide scale analysis of NDVI trends covering the two municipalities and several coastal barangays to arrive at a mean growth trend. It was later suggested that there may be site specific differences in the recovery of mangroves. 


\subsection{Vegetation and Moisture Indices}

The NDVI is an effective vegetation index commonly used in mapping mangroves as it can estimate canopy cover and forest health (Alatorre et al., 2016; Lovelock et al., 2017). NDVI calculates the ratio between the red and near infrared values (see Table 1, Equation 1) to quantify the greenness of the vegetation, allowing for understanding its density and health (U.S. Geological Survey, 2021b).

However, other indices, such as Enhanced Vegetation Index (EVI) and Modified Soil Adjusted Vegetation Index (MSAVI) are more robust than the NDVI and can also monitor plant health and identify mangroves (Younes et al., 2019). The EVI, like the NDVI, also measures the greenness of the vegetation, but is more sensitive to dense vegetation. It also accounts for canopy background noise and some atmospheric conditions (U.S. Geological Survey, 2021a). It is calculated as a ratio between the red and infrared bands but includes a canopy background index $(\mathrm{L}=1)$, coefficients for atmospheric resistance $(\mathrm{C} 1=6$ and $\mathrm{C} 2=$ 7.5) and the blue band (see Table 1, Equation 2). The MSAVI, on the other hand, corrects for the effect of the bare soil that can interfere with the vegetation signal. Its function also makes use of the red and infrared bands (see Table 1, Equation 3).

Another useful index in characterizing mangrove intactness or degradation is the Normalized Difference Moisture Index (NDMI) (Lee et al., 2021). It is calculated as a ratio between the near-infrared (NIR) and short-wave infrared (SWIR) bands (see Table 1, Equation 4) and can be applied to determine vegetation water content (U.S. Geological Survey, 2021c).

\begin{tabular}{lc}
$\begin{array}{l}\text { Spectral } \\
\text { Index }\end{array}$ & Formula \\
\hline NDVI & $\frac{\mathrm{NIR}-\mathrm{RED}}{\mathrm{NIR}+\mathrm{RED}}$ \\
EVI & $2.5 * \frac{(\mathrm{NIR}-\mathrm{RED})}{(\mathrm{NIR}+6 * \mathrm{RED}-7.5 * \mathrm{BLUE})+1}$ \\
MSAVI & $\frac{2 * \mathrm{NIR}+1-\sqrt{(2 * \mathrm{NIR}+1)^{2}-8 *(\mathrm{NIR}-\mathrm{RED})}}{2}$ \\
& $\frac{\mathrm{NIR}-\mathrm{SWIR} 1}{\mathrm{NIR}+\mathrm{SWIR} 1}$
\end{tabular}

Table 1: Spectral Indices for time series analysis

A recent study on the mangrove forest degradation and regeneration in the eastern coast of the Red Sea (Aljahdali et al., 2021) made use of a time series analysis of the moisture and vegetation indices to monitor mangrove health. The MSAVI and NDMI performed best in identifying vegetation trend patterns and forest disturbance and recovery in terms of water stress, respectively.

This study takes off from Cabello et. al. (2021) and aims to further examine the recovery of mangroves by analyzing the time series trends of the different vegetation and moisture indices to characterize the varying rates of growth from different locations. This study offers a finer scale analysis of mangrove recovery in terms of the spatial resolution and indicators of recovery.
Monitoring post-typhoon mangrove recovery can provide further insights on how events such as typhoons and storm surges affect the ecosystem dynamics of mangroves and aids in the formulation of intervention measures that consequently increase a community's resilience to the effects of climate change.

\section{METHODOLOGY}

\subsection{Study area}

The municipalities of Lawaan and Balangiga are in the southern portion of the province of Eastern Samar. It has a coastline length of approximately $36 \mathrm{~km}$. The mangrove patches studied were the recovered areas identified by Cabello et. al. (2021). Only the mangrove patches with area greater than 900 sqm, which cover more than 1 pixel in Landsat-8 image, were selected to reduce the probability that these zones were misclassified. A total of thirtynine (39) data points scattered across the Lawaan-Balangiga coastal barangays were considered (Figure 1).

\subsection{Satellite Image Data}

Atmospherically corrected surface reflectance products from Landsat 8 images taken from 2013 to 2020 were used for the study. NDVI, EVI, MSAVI, and NDMI were calculated and added as bands to each image which were then masked for clouds. A time series of each index was generated for each of the 39 data points. The image data were accessed and processed using GEE.

\subsection{Time Series Analysis of Vegetation Indices}

The NDVI, EVI, MSAVI, and NDMI time series during the recovery period were downloaded and analyzed based on the slopes of the trend lines computed using linear regression in Excel. The expected range of values for NDVI, MSAVI, and NDMI are between -1 to 1 . Positive values for the NDVI and MSAVI identify vegetation, and values closer to 1 indicate health and high vegetation activity. Positive values of EVI also indicate vegetation. Positive NDMI values mean low water stress in the mangrove area suggesting health and intactness. Increasing NDVI, EVI, and MSAVI were interpreted as increasing canopy cover. The positive trend in the NDMI was interpreted as increasing water content, all indicative of mangrove health and recovery. The variation in the trendline slopes was taken to indicate the different rates of recovery across the data points and their locations. The correlation between the slopes of each index was calculated. A high correlation between indices, with an Rvalue close to 1 , was interpreted to support the general greening pattern across the study area.

\subsection{Trend Analysis}

A Mann Kendall trend test, commonly used to analyze data collected over time, was also done to confirm the increasing or decreasing trends in the data. In the Mann-Kendall test, the null hypothesis that assumes that there is no trend in the series was tested against an alternative hypothesis that indicates that there exists a significant trend in the series. The test was conducted using XLSTAT software, which solves the Mann-Kendall S Statistic and the p-value for every time series. When the value of $\mathrm{S}$ is high and the $\mathrm{p}$-value is less than the significance level $\alpha$ (alpha) $=0.05$, the null hypothesis is rejected, indicating a trend in the time series. 


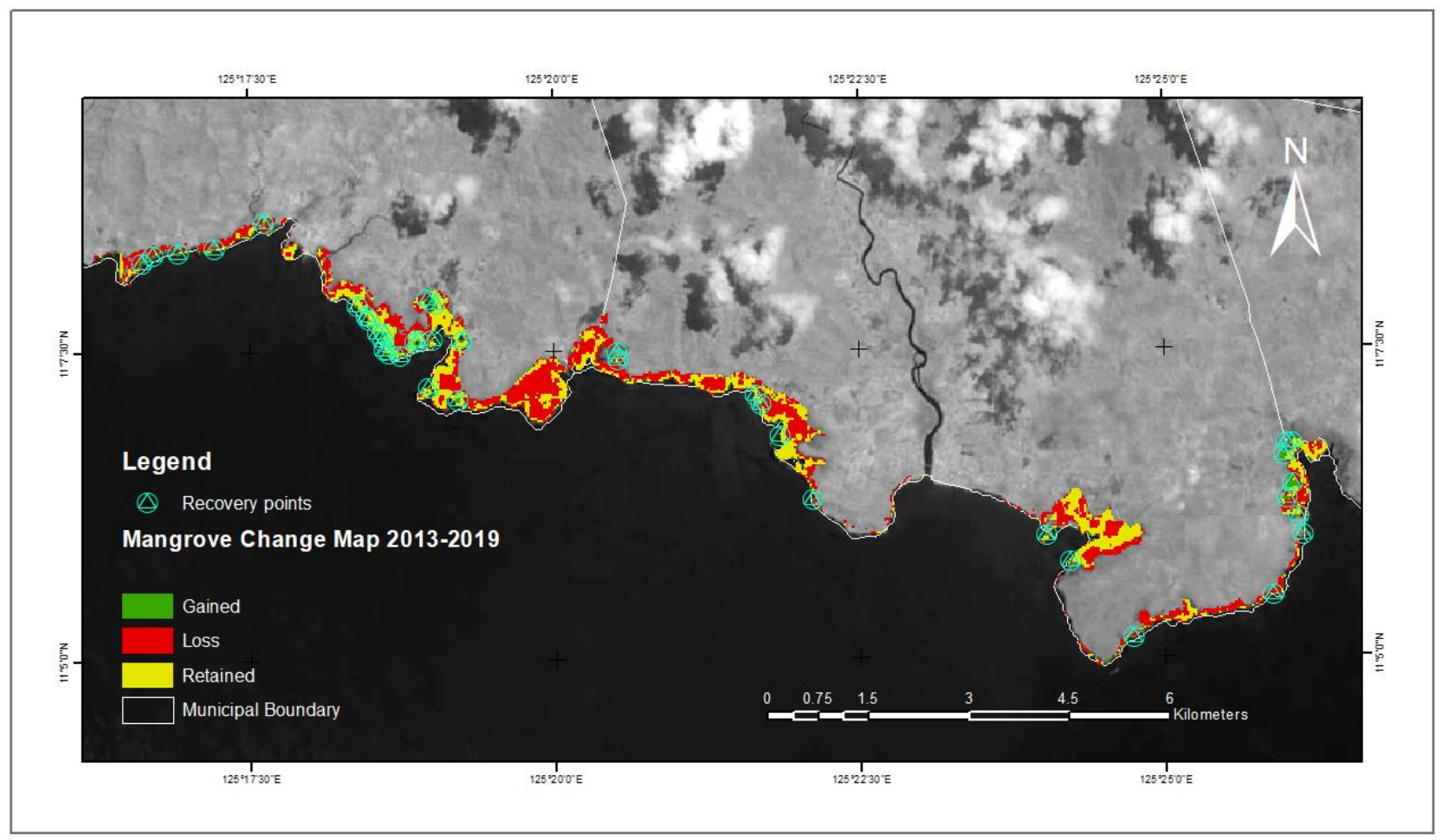

Figure 1: Mangrove recovery points across the study area from mangrove change map (2013-2019) (modified from Cabello et. al. 2021)

\section{RESULTS AND DISCUSSION}

Table 2 shows the mean values of the indices - from the time following the typhoon in 2014 to after period of recovery in 2020. The positive values and increase in the mean show there is growth in vegetation for the recovery points.

\begin{tabular}{ccc}
\hline & $\mathbf{2 0 1 4}$ & $\mathbf{2 0 2 0}$ \\
\hline EVI & 0.66 & 0.79 \\
MSAVI & 0.22 & 0.29 \\
NDMI & 0.11 & 0.20 \\
NDVI & 0.17 & 0.23 \\
\hline
\end{tabular}

Table 2: Mean values of indices in 2014 and 2020

The time series plots of the indices show an upward trend in the values for most of the points in the study area (Figure 2). The slope of trend lines for NDVI, MSAVI and NDMI are similar, while the slope of the EVI trendline is steeper. The positive slope values support the interpretation of growth in vegetation.

The slopes of the trendlines for indices were plotted for the damage and recovery period (Figure 3 and Figure 4). The horizontal axis for the slope of the trend lines corresponds to the data points. These said points were arranged according to their locations along the coastline from west to east.

The negative values in the plot for the damage period show a general decrease in the vegetation and moisture index values, indicating mangrove canopy loss. The slopes of the trendlines show positive values during the recovery period indicating that across the indices, there was a general increase in value and recovery in mangrove areas.
The plots also show the variation in the damages and the rates of recovery. Points located on the eastern portion took the most damage, as evidenced by the significant negative slopes in 2013 to 2014. However, these points also recorded a faster rate of recovery based on the steeper slopes in the 2014-2020 plot.

It appears that mangrove areas that experienced more damages during the typhoon event have recovered faster. It may be assumed that the mangrove cover loss made way for new growth and colonization.

There is also a high correlation among the trend slopes of the EVI, MSAVI, NDVI, and NDMI (Table 3).

\begin{tabular}{ccccc}
\hline & EVI & MSAVI & NDMI & NDVI \\
\hline EVI & 1.00 & & & \\
MSAVI & 0.96 & 1.00 & & \\
NDMI & 0.91 & 0.93 & 1.00 & \\
NDVI & 0.96 & 1.00 & 0.94 & 1.00 \\
\hline
\end{tabular}

Table 3: Correlation of the slopes of trendlines of the vegetation and moisture indices with $\mathrm{p}$-values $<0.01$

The NDVI has the highest correlation with MSAVI (1.00) since both make use of the NIR and RED bands in highlighting vegetation. The high correlation of NDVI and NDMI $(\mathrm{r}=0.94)$ also indicates low to mid-canopy cover with low water stress. The higher the trend slope values observed among clusters of points indicate that at different areas, there are varying rates of recovery. 


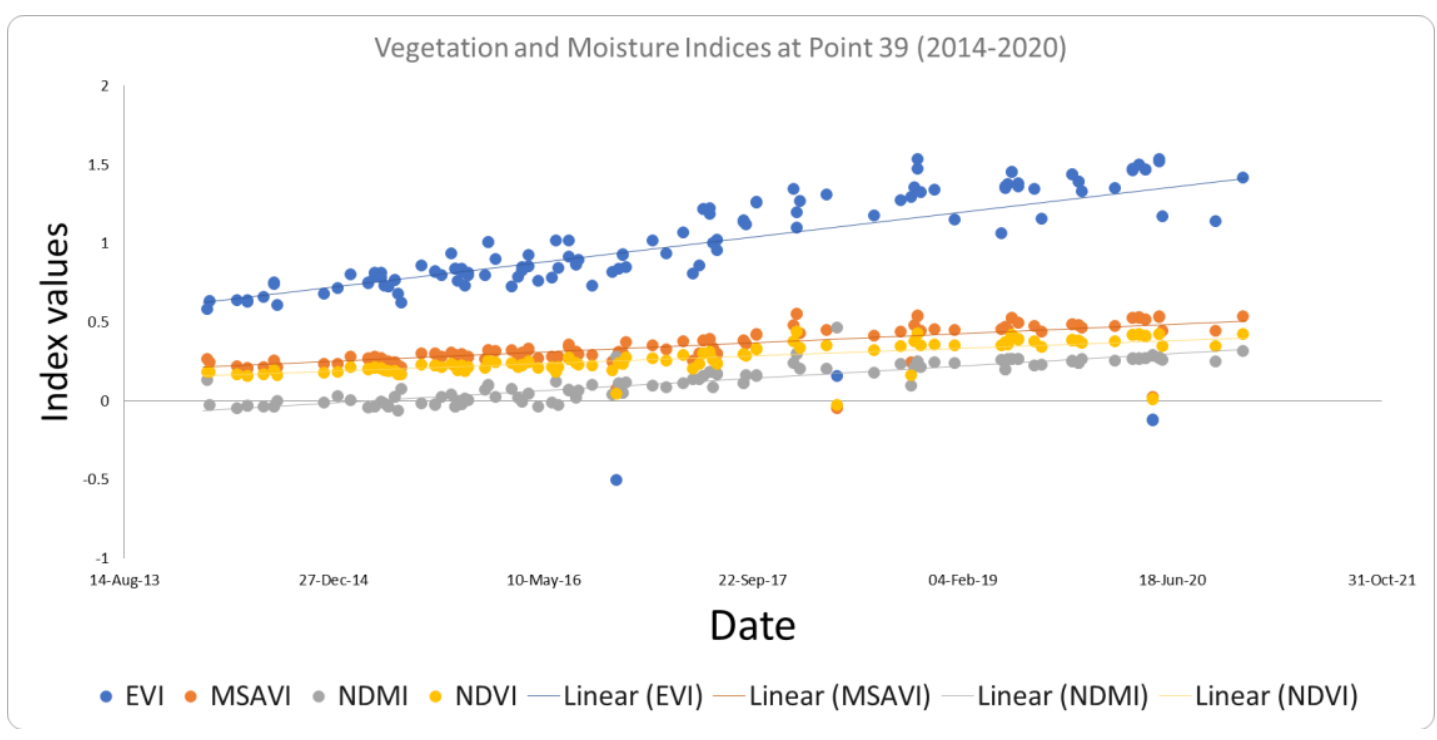

Figure 2: Sample Time Series plot of Indices for one point

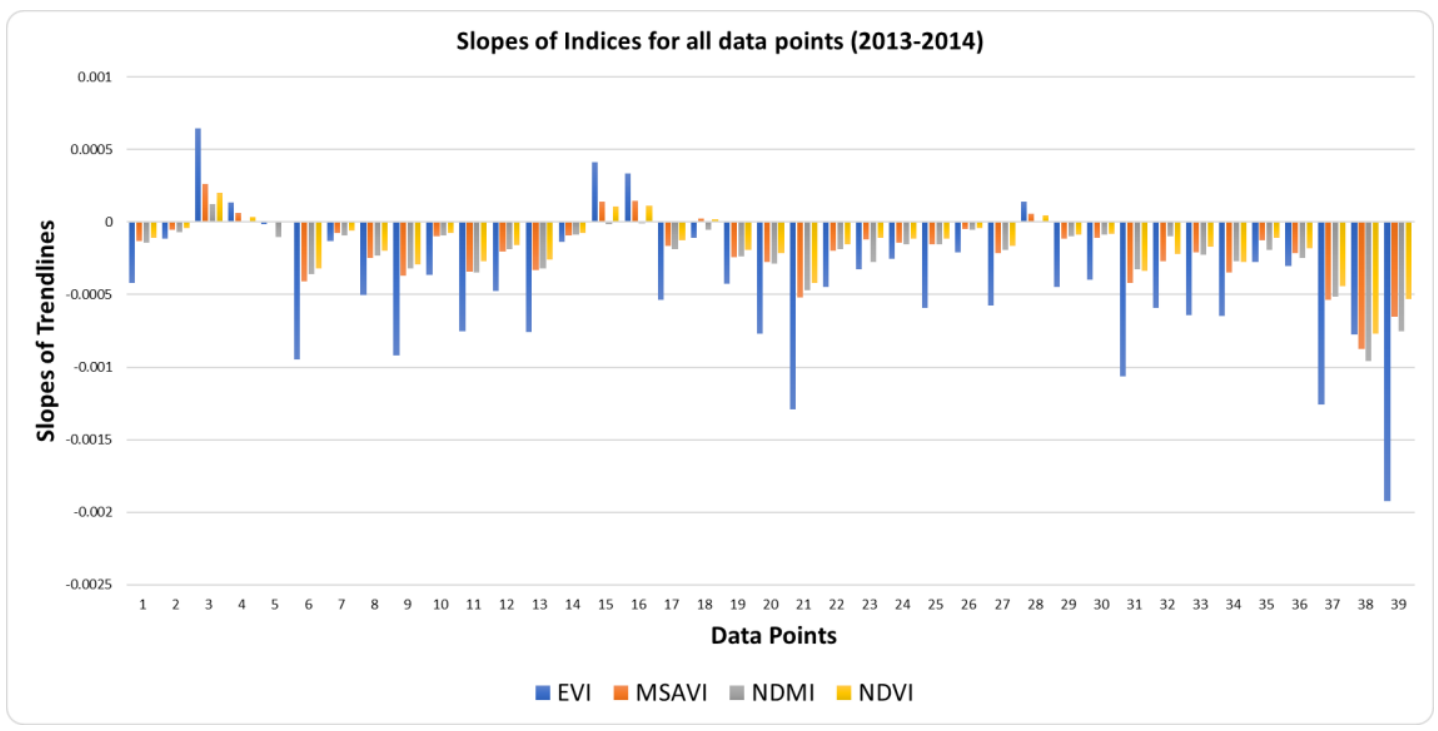

Figure 3: Slopes of Indices for all data points (2013-2014)

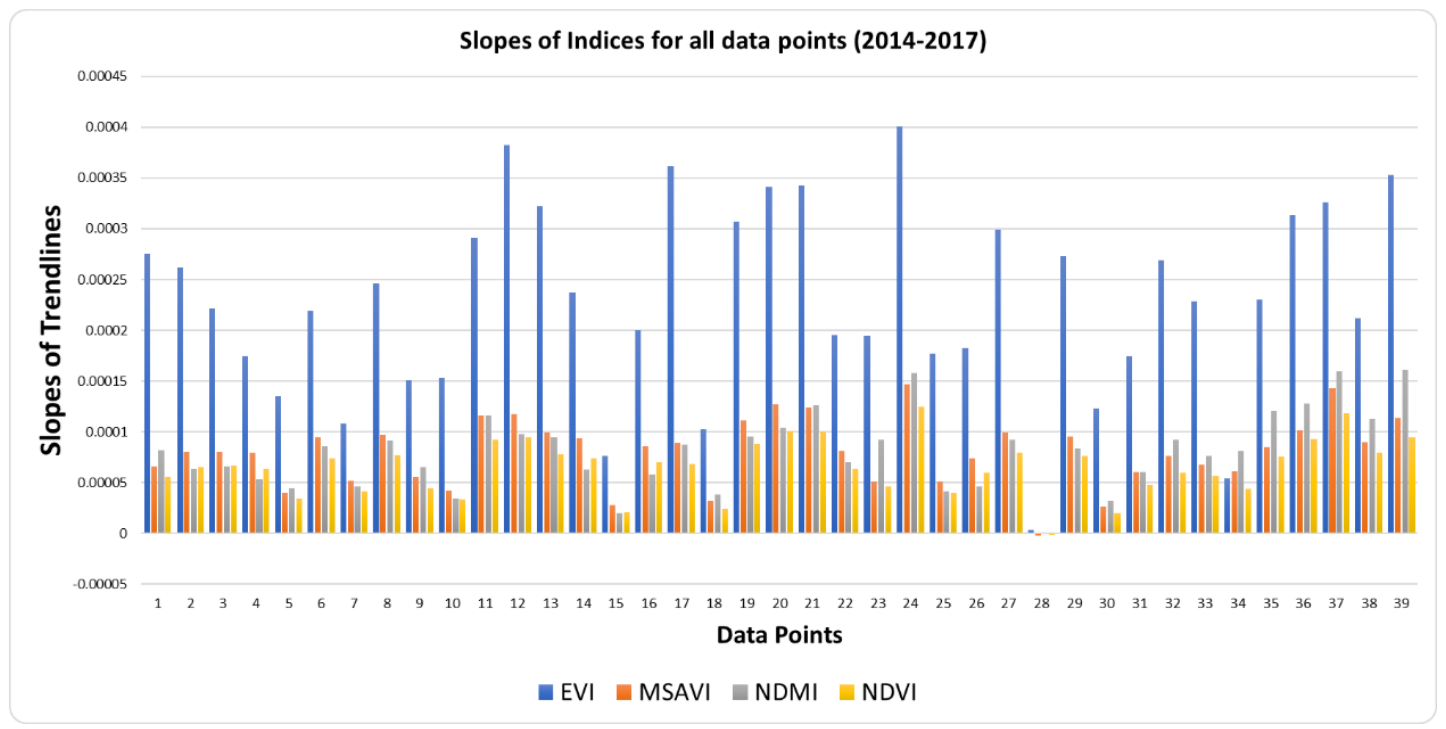

Figure 4: Slopes of Indices for all data points (2014-2020) 


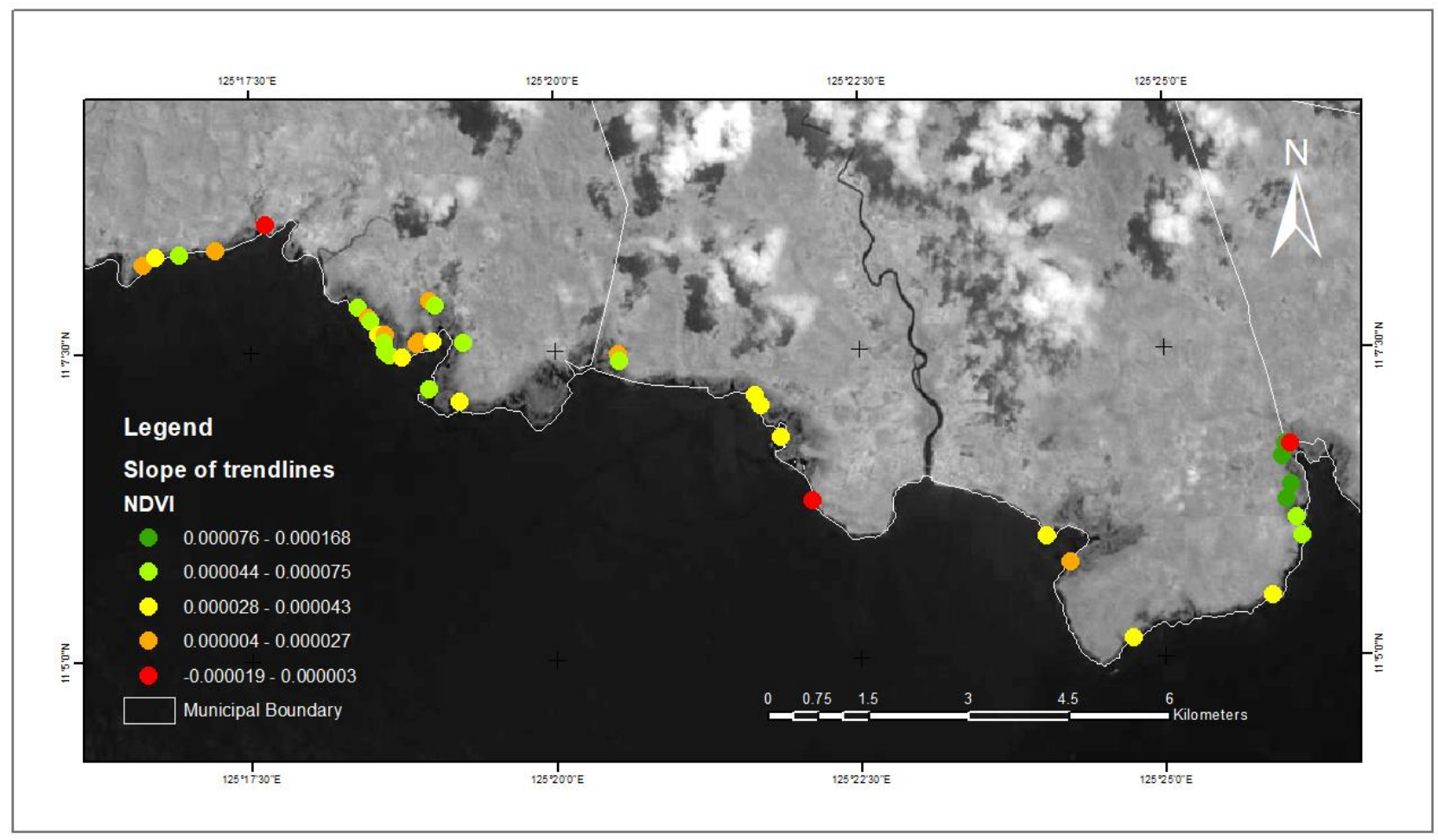

Figure 5: Estimated relative rates of mangrove "recovery" across the study area based on the slope of NDVI trend lines

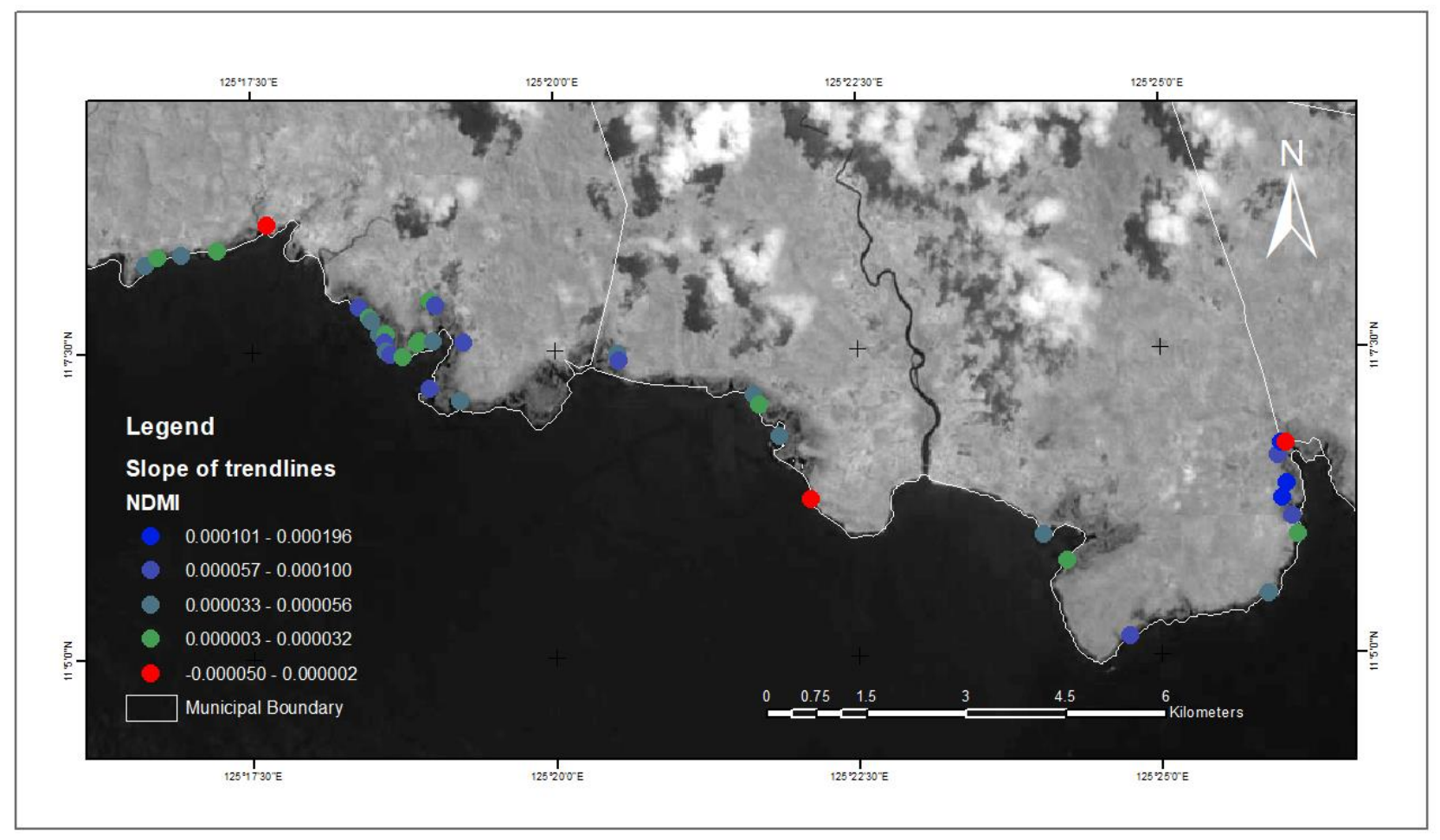

Figure 6: Estimated relative rates of mangrove "recovery" across the study area based on the slope of NDMI trend lines 
Results of the Mann Kendall trend test revealed that 34 of the 39 data points $(87 \%)$ have p-values less than 0.05 for all the indices, showing that there was a significant positive trend across the time series of the different indices. This further supports the initial interpretation that for most of the data points, there is evident mangrove recovery.

Mapping the slopes of the NDVI and NDMI trend lines show similar recovery rates among clusters of data (Figure $\mathbf{5}$ and Figure 6). From this, probable factors that contribute to the mangrove recovery can now be explored, including the effect of the location of the mangroves with respect to the coastline and river mouths. Proximity to urban areas and the adjacent vegetation and reef flat could also be possible explanatory variables.

\section{CONCLUSIONS AND RECOMMENDATIONS}

The research was able to corroborate the previous study on mangroves in Lawaan-Balangiga, by presenting positive trend results in the identified recovered areas. It was also able to contribute to the literature by including time series trend analysis of other vegetation and moisture indices as indicators of posttyphoon growth and recovery. These indices, including their combination, can be explored to detect post-typhoon recoveries further.

Further statistical analysis is needed to characterize the varying rates of recovery for the different data clusters. Additional time series analysis for the areas identified as 'retained' and 'lost' are also recommended to compare the growth rates of the mangroves in these areas with those of the recovered mangroves.

These trends, however, would still have to be validated by collecting and comparing biophysical parameters in the field.

The next step of the research would be to identify the factors that contribute to the varying rates of recovery in the areas and to evaluate how this can affect the carbon sequestration rates of recovering mangroves.

\section{AKNOWLEDGEMENTS}

This research was made possible by the support of the 'Upgrading and Promoting the Comprehensive Assessment and Conservation of Blue Carbon Ecosystems and their Services in the Coral Triangle' (UP BlueCARES) Project and the 'The Project for Comprehensive Assessment and Conservation of Blue Carbon Ecosystems and their Services in the Coral Triangle (BlueCARES) funded by Japan International Cooperation Agency (JICA) and Japan Science and Technology Agency (JST) under the SATREPS Program.

\section{REFERENCES}

Alatorre, L. C., Sánchez-Carrillo, S., Miramontes-Beltrán, S., Medina, R. J., Torres-Olave, M. E., Bravo, L. C., Wiebe, L. C., Granados, A., Adams, D. K., Sánchez, E., \& Uc, M. (2016). Temporal changes of NDVI for qualitative environmental assessment of mangroves: Shrimp farming impact on the health decline of the arid mangroves in the Gulf of California (1990 2010). Journal of Arid Environments, 125, 98-109. https://doi.org/10.1016/J.JARIDENV.2015.10.010

Aljahdali, M. O., Munawar, S., \& Khan, W. R. (2021). Monitoring Mangrove Forest Degradation and Regeneration: Landsat Time Series Analysis of Moisture and Vegetation
Indices at Rabigh Lagoon, Red Sea. Forests 2021, Vol. 12, Page 52, 12(1), 52. https://doi.org/10.3390/F12010052

Baloloy, A. B., Blanco, A. C., Raymund Rhommel, R. R. C., \& Nadaoka, K. (2020). Development and application of a new mangrove vegetation index (MVI) for rapid and accurate mangrove mapping. ISPRS Journal of Photogrammetry and Remote Sensing, 166, 95-117. https://doi.org/10.1016/J.ISPRSJPRS.2020.06.001

Cabello, K. E., Germentil, M. Q., Blanco, A. C., Macatulad, E. G., \& Salmo III, S. G. (2021). POST-DISASTER ASSESSMENT OF MANGROVE FOREST RECOVERY IN LAWAAN-BALANGIGA, EASTERN SAMAR USING NDVI TIME SERIES ANALYSIS. ISPRS Annals of the Photogrammetry, Remote Sensing and Spatial Information Sciences, V-3-2021, 243-250. https://doi.org/10.5194/ISPRSANNALS-V-3-2021-243-2021

Conservation International. (2008). Economic Values of Coral Reefs, Mangroves, and Seagrasses A Global Compilation 2008. www.communities.coastalvalues.org/

Delfino, R. J., Carlos, C., David, L., Lasco, R., \& Juanico, D. E. (2015). Perceptions of Typhoon Haiyan-affected communities about the resilience and storm protection function of mangrove ecosystems in Leyte and Eastern Samar, Philippines. Climate, Disaster and Development Journal, 1(1). https://doi.org/10.18783/cddj.v001.i01.a03

FAO. (2021). FAO and the Typhoon Haiyan in the Philippines : $F A O$ in Emergencies. https://www.fao.org/emergencies/crisis/philippines-typhoonhaiyan/intro/en/

IUCN. (2021). Mangroves and coastal ecosystems | IUCN. https://www.iucn.org/theme/marine-and-polar/ourwork/climate-change-and-ocean/mangroves-and-coastalecosystems

Lee, C. K. F., Duncan, C., Nicholson, E., Fatoyinbo, T. E., Lagomasino, D., Thomas, N., Worthington, T. A., \& Murray, N. J. (2021). Mapping the Extent of Mangrove Ecosystem Degradation by Integrating an Ecological Conceptual Model with Satellite Data. Remote Sensing 2021, Vol. 13, Page 2047, 13(11), 2047. https://doi.org/10.3390/RS13112047

Long, J., Giri, C., Primavera, J., \& Trivedi, M. (2016). Damage and recovery assessment of the Philippines' mangroves following Super Typhoon Haiyan. Marine Pollution Bulletin, 109(2), 734-743. https://doi.org/10.1016/J.MARPOLBUL.2016.06.080

Losada, I. J., Beck, M. W., Menéndez, P., Espejo, A., Torres, S., Díaz-Simal, P., Fernández, F., Abad, S., Ripoll, N., García, J., Narayan, S., \& Trespalacios, D. (2017). Valuation of the Coastal Protection Services of Mangroves in the Philippines. www.wavespartnership.org

Lovelock, C. E., Feller, I. C., Reef, R., Hickey, S., \& Ball, M. C. (2017). Mangrove dieback during fluctuating sea levels. Scientific Reports, 7(1). https://doi.org/10.1038/S41598-01701927-6

NOAA. (2021). What is a mangrove forest? 
Sarhan, M., \& Tawfik, R. (2018). The Economic Valuation of Mangrove Forest Ecosystem Services: Implications for Protected Area Conservation. The George Wright Forum •, 35(3), 341.

Seriño, M. N., Ureta, J. C., Baldesco, J., Galvez, K. J., Predo, C., \& Seriño, E. K. (2017). Valuing the Protection Service Provided by Mangroves in Typhoon-hit Areas in the Philippines. www.eepsea.org.

The World. (2021). Philippine town credits preserved mangroves with stopping Typhoon Haiyan's storm surge. https://www.pri.org/stories/2013-11-29/saved-mangrovesphilippine-town-dodges-haiyans-storm-surge

U.S. Geological Survey. (2021a). Landsat Enhanced Vegetation Index. $\quad$ https://www.usgs.gov/core-sciencesystems/nli/landsat/landsat-enhanced-vegetation-index?qtscience_support_page_related_con $=0 \# q \mathrm{q}-$ science_support_page_related_con

U.S. Geological Survey. (2021b). Landsat Normalized Difference Vegetation Index. https://www.usgs.gov/corescience-systems/nli/landsat/landsat-normalized-differencevegetation-index?qt-science_support_page_related_con=0\#qtscience_support_page_related_con

U.S. Geological Survey. (2021c). Normalized Difference Moisture Index. https://www.usgs.gov/core-sciencesystems/nli/landsat/normalized-difference-moisture-index

World Vision. (2021). 2013 Typhoon Haiyan: Facts, FAQs, and how to help | World Vision. https://www.worldvision.org/disaster-relief-news-stories/2013typhoon-haiyan-facts\#where-hit

Younes, N., Joyce, K. E., Northfield, T. D., \& Maier, S. W. (2019). The effects of water depth on estimating Fractional Vegetation Cover in mangrove forests. International Journal of Applied Earth Observation and Geoinformation, 83, 101924. https://doi.org/10.1016/J.JAG.2019.101924 